\title{
In Australia what is the Best Thing About Being an Indigenous ${ }^{1}$ Father?
}

Jacob Prehn $^{\mathrm{a}^{*}}$, J. Baltra-Ulloa ${ }^{\mathrm{a}}$, J. Canty ${ }^{\mathrm{a},}$ and M. Williamson ${ }^{\mathrm{a}}$

a Social Work, School of Social Sciences, University of Tasmania, Hobart, Tasmania.

Dr. Jacob Prehn - Corresponding Author

Jacob.Prehn@utas.edu.au

PB 22, University of Tasmania, Hobart, 7001

Dr. Jacob Prehn is an Indigenous Fellow and Lecturer in Social Work at the University of Tasmania. Jacob is an Early Career Researcher whose publications include qualitative and quantitative methods exploring topics such as Indigenous masculinity, health and wellbeing, education, and Indigenous Data Sovereignty.

Dr. Joselynn Baltra-Ulloa

Joselynn Baltra-Ulloa (Jos) co-Head of Social Work at the University of Tasmania. Originally from Chile, she came to Australia as a refugee. She is amongst a group of First Nations scholars across the globe that conducts research and community work with a focus on decolonisation and integrating Southern knowledges.

\section{Dr. Justin Canty}

Justin Canty is Lecturer in Social Work at the University of Tasmania. He belongs to white Australian settler-colonial culture and marginalised communities within that culture (LGBTIQA+). He collaborates in this research led by First Nations colleagues with humility, respect for sovereignty, and working to decolonise social work practice.

\section{Matthew Williamson, PhD Candidate}

Matthew Williamson is a $\mathrm{PhD}$ candidate at the University of Tasmania. Matthew is Australian and British by citizenship and culturally a White-Australian. He has an ongoing interest in reconciliation between settlers and Aboriginal and Torres Strait Islander peoples.

\footnotetext{
${ }^{1}$ In this paper we use the term Indigenous to refer to Aboriginal and/or Torres Strait Islander peoples unless otherwise stated.
} 


\begin{abstract}
In Australia, the ongoing structure of settler colonialism has meant understandings of Indigeneity continue to uphold deficit narratives about the lives of Indigenous peoples. The narrative that predominates for Indigenous fathers is often the labels of dysfunctionality, deviance, and disengagement with their children. Using the Longitudinal Study of Indigenous Children data, this paper seeks to challenge these deficit narratives to shed light not only on the strengths Indigenous fathers report of their experiences of fatherhood, but also on how fatherhood could be reconceptualised under an Indigenous epistemology. We applied a content analysis to answers generated by the question: what is the best thing about being your child's father? The range of responses suggested a most positive and child centred experience of fatherhood where Indigenous fathers report the sharing of love and culture with their children as direct contributions to children growing strong. We followed recent efforts and used a strengths-based approach in Indigenous fathering research, to counter deficit narratives of Indigenous fatherhood and explore how an Indigenous standpoint can inform approaches to social, cultural, and health and wellbeing practices.
\end{abstract}

\title{
Implications
}

- The findings highlight the significant role of a strengths-based approach focused on relationality to challenge unfair and inaccurate deficit-based narratives of Aboriginal and/or Torres Strait Islander fathers.

- The paper identifies the influence of deficit-based narratives of Aboriginal and/or Torres Strait Islander fathers as an urgent issue for social work practice to address as such narratives may be implicated in contributing to excessively high rates of child removal. 
- Key Words: Aboriginal; Torres Strait Islander; Dad; Strengths-Based Parenting; Social Work; Relationality; Supports.

In Australia, there exists a pervasive, persistent, and unfair deficit-based narrative pertaining to Indigenous men and their role as fathers ${ }^{2}$ (ABC News, 2016a; Wild \& Anderson, 2007). These unfair deficit-based narratives of Indigenous men and Indigenous fathers include damaging stereotypes such as being excessively disengaged (ABC News, 2016a), deviant (Wild \& Anderson, 2007), and dysfunctional (Bringing Them Home, 1997). These deficitbased narratives are embedded in the ongoing structure of settler colonialism (Wolfe, 1999), which is defined by Barker and Lowman (2020, p. 1) as:

“a distinct type of colonialism that functions through the replacement of Indigenous populations with an invasive settler society that, over time, develops a distinctive identity and sovereignty... Settlers and their governments hold extraordinary power over Indigenous peoples, including the ability to apprehend children, to prevent people from leaving official ‘reserve' lands (or conversely, to expel individuals or families from reserved territories), to control employment, and even to summarily direct police or military forces against Indigenous people. These extreme powers are exercised based on carefully constructed racist narratives. Consider the way Indigenous people have (and are) considered to be savage, with men often portrayed as violent, women as hyper-sexualised, and both in need of care from the ‘civilised' settler-colonial state”.

\footnotetext{
${ }^{2}$ We recognise that in an Indigenous lifeworld, the conceptualisation of 'father' can include biological and nonbiological family members, as well as others from the broader Indigenous community such as uncles, grandfathers, cousins, etc.
} 
Settler colonialism has formed the foundation for the damaging, racist, and unjust deficitbased narratives of Indigenous men and their roles as fathers. Similar to dominant representations of other marginalised boys and men, Indigenous fathers are problematically theorised as more violent or neglectful as a response to powerlessness or oppression (Elliott \& Roberts, 2020). For Indigenous men generally and Indigenous fathers specifically, impacts of colonisation and poverty are given explanatory power as drivers of "toxic behaviour" in the pursuit of power over others (Elliott \& Roberts, 2020). Such damaging assumptions pervade the social fabric, including institutions and fields of social work practice.

The ongoing structure of settler colonialism in Australia has contributed to the formation of unfair and damaging narratives pertaining to Indigenous fathers (Canuto et al., 2020; Wolfe, 1999). These narratives often generalise individual Indigenous fathering shortcomings to all Indigenous fathers, a process which does not commonly occur for White Australian fathers. These narratives are characterised by invisibility or absence of Indigenous fathers on the one hand and their depiction as perpetrators of gendered violence on the other. The Northern Territory Emergency Response Act 2007, an event which resulted in the Australian government using its own military forces against Aboriginal people, was partially justified because of the so-called excessively deviant nature of Indigenous fathers and Indigenous men (Konishi, 2011). A graphic example of such narratives is the infamous Bill Leak Cartoon, invoking stereotypes of Indigenous fathers as too intoxicated to remember their child's name, simultaneously labelling Indigenous youths as delinquents (ABC News, 2016a). Settler colonialism as a system is obsessed with the 'elimination of the native' (Wolfe 2006: 387) through methods such as assimilating Indigenous fathering practices to White middle-class parental norms, evident in areas such as so called ‘child protection’ organisations (Krakouer, 2019), and in the emasculation of Indigenous men not adhering to the violent toxicity stemming from hegemonic settler colonial masculinity (Morgensen 2015; Prehn 2021). 


\section{Indigenous Fatherhood and Relationality}

The notion of relationality between Indigenous fathers, their children, and Indigenous epistemes is a key component of fatherhood. From an Indigenous worldview (inclusive of epistemology, ontology, and axiology), the concept of relationality is generally more holistic than a Western perspective (Dockery 2020; Dudgeon et al., 2014; Foley, 2003; Fredericks 2009; Martin 2008; Walter \& Baltra-Ulloa 2021). For many Indigenous peoples, relationality refers to "our lived relation to other human beings, other living creatures, and to the nonliving entities with whom we share our spaces and the planet” (Ritchie, 2013, p. 307). The centrality of the relationships Indigenous fathers (inclusive of broader notions of Indigenous fathering such as Uncles) have with their children has been explored by Canuto et al. (2019), while Prehn et al. (2020) have explored relationality between Indigenous fathers, children, and the sharing of Indigenous cultural practices.

Graham (2014) presents relationality as essential to enabling Indigenous being, belonging, and connection, crucial to Indigenous people learning how to be in the world. This is critical to Indigenous children and connects logically with Indigenous parenting. Relationality offers a frame that disrupts the 'disinterested and disengaged’ stereotype invoked in policy and public discourses. This has important implications for social work practice and other professions collaborating with Indigenous fathers and families. Two specific issues offer important illustrations: first, provision of child rearing support to Indigenous fathers in context of ongoing impacts of settler colonialism (Canuto et al., 2020; Collard et al., 2016; Prehn et al., 2020).; and second, influences of these unfair and damaging narratives in excessively disproportionate rates of child removal from Indigenous fathers, mothers, families, and other caregivers (Australian Institute of Health and Welfare, 2021; Krakouer, 2019; Hunter et al., 2020). 


\section{Strengths-based Approaches}

A strengths-based approach offers a key social work method to counter these deficit-based narratives about Indigenous fathers. The strengths perspective was developed as a counter to deficit-based thinking, which typically reduces an individual, family, or community to their problems or shortcomings (Rapp, 1997; Saleebey, 1996). In the Indigenous sphere, strengthsbased approaches have been used in: health and wellbeing (Brough et al., 2004; Tsey et al., 2007); children and adolescents (Armstrong et al., 2012; Priest et al., 2012); families (Walker \& Shepherd, 2008; Whiteside et al., 2016); and in research (Bainbridge et al., 2013; Fogarty et al., 2018).

Saleebey's (1996) six key strength-based principles offer a meaningful framework in the Indigenous fathering space. They highlight areas where strengths can be unearthed, embedded, built upon, and amplified in spontaneous actions such as \#IndigenousDads as well as deliberate application to social work engagement with Indigenous fathers and their children. These six key principles are:

1) "Every individual, group, family, and community have strengths;

2) Trauma, abuse, illness, and struggle may be injurious, but they may also be sources of challenge and opportunity;

3) Assume that you do not know the upper limits of the capacity to grow and change, and take individual, group, and community aspirations seriously;

4) We best serve people by collaborating with them;

5) Every environment is full of resources; and

6) Caring, caretaking, and context”.

Strengths-based approaches to Indigenous fathering and the subsequent sharing of these narratives are important to displace settler colonial deficit thinking. To address this, we 
applied content analysis to Indigenous fathering data from the Longitudinal Study of Indigenous Children (LSIC) Wave 5 (B \& K Cohort). We explore short qualitative responses from the question: "what's the best thing about being $<$ Study child $>$ 's $<$ Dad/Dad relationship?>” (Item bdi1_t). ${ }^{3}$ The results suggest encouraging and warm-hearted reasons such as nurturing growth, doing things together, happiness, and love. These, in turn, connect with relationality and relationships as key explanatory concepts which offer more sophisticated theorising of Indigenous fathering, counter to prevailing dominant deficit narratives. We discuss relationality specifically within an Indigenous epistemic frame as a lens for understanding the analysis and to challenge what are often superficial and thin interpretations (Geertz, 1973). We explore these results further in relation to social work practice and highlight the importance of using a strengths-based approach with Indigenous fathers.

Indigenous fathers and their children spontaneously initiated a strengths-based response to the notorious Bill Leak cartoon (ABC News, 2016a). The Leak cartoon simultaneously masks and perpetuates the ongoing structure of settler colonialism, concealing its damage on the lives of Indigenous peoples by making the stereotype appear 'natural' (Barker \& Lowman, 2020; Wolfe, 1999). In response, the social media movement “\#IndigenousDads” (ABC News, 2016b) organically used a strengths perspective to promote a counter-narrative of positive and connected Indigenous fathers and their children. This movement inspired Indigenous fathers and their children to share pictures on social media platforms depicting love for each other, and pride in Indigenous culture. Grassroots initiatives like this lead the way for institutions, professions, communities, systemic, and individual engagement with strengths-based perspectives and theorising of Indigenous fathering.

\footnotetext{
${ }^{3}$ This represents the variable name in the Longitudinal Study of Indigenous Children Data Dictionary (Department of Social Services, 2018).
} 
In the Indigenous fathering space there has been a slow but gradual increase in the number of publications over the last two decades (Canuto et al., 2020). This growing body of literature has considered components of Indigenous fatherhood such as: fathers practicing and sharing Indigenous culture with their children (Collard et al., 2016; Prehn et al., 2020); the need to provide Indigenous fathers with supports to enhance their fathering capabilities (Males in Black Inc. \& Wesley, 2006; Newell et al., 2006); and the importance of using strengths-based approaches (Canuto et al., 2020; Reilly \& Rees, 2018). Despite this increase, there remain a number of significant gaps in the literature (Canuto et al., 2020). As identified by Canuto et al. (2020) in their scoping review, in Australia there are only eight studies pertaining to Indigenous fathers. Some of the gaps in the Indigenous fathering space include localised and region-specific research with Indigenous fathers, acknowledging the many differences in Aboriginal and Torres Strait Islander cultural practices and fathering epistemes (see for example Gee et al. (2014) and their discussion on differences in Indigenous cultures more generally). Other gaps in the Indigenous fathering literature include the minimal use of national survey data pertaining to Indigenous fatherhood (Prehn et al., 2020); publications using Indigenous standpoint theory which centre Indigenous epistemes (Foley, 2003); and the broader use of strength-based approaches, with focus on specific areas like the relationship between Indigenous fathers and their children, rather than deficits (Canuto et al., 2020). Further, the troubling health and wellbeing outcomes experienced by Indigenous men and how this can negatively affect their role as fathers should be taken into consideration (Australian Department of Health and Ageing, 2010; Canuto et al., 2018; Prehn \& Ezzy, 2020). 


\section{The Current Research}

This paper aims to grow the strengths-based and relationality literature on Indigenous fatherhood by exploring the question: what's the best thing about being their child's dad (Item bdi1_t)? We use analysis of empirical data to centre Indigenous fathers' experiences of fatherhood as positively relational, directly challenging prevailing assumptions and negative biases. The paucity of research evidence adds weight to our proposition that much of the social discourses about Indigenous fathering are based in assumption, inference, and stereotype rather than the careful and critical analysis of empirical data that these multiply marginalised experiences deserve. As such, the dominant narratives can be described using Geertz's (1973) notion of ‘thin description'. In our discussion, we aim to 'thicken' the description through analysing empirical data and applying an Indigenous epistemic frame of relationality that contributes to theorising the results of applying a strengths perspective to data analysis.

\section{Method}

\section{Research Design}

This paper prioritises the use of Indigenous standpoint theory as articulated by Dennis Foley (2003). The primary author is Worimi (Aboriginal) and actively involved in his local Aboriginal community, another author is Mapuche (First Nations from Chile), the other two authors are White Australians who acknowledge their ethnic social positioning and the privilege this affords them. In Australia, such positioning acknowledgements are particularly important when working in the Indigenous sphere because of the ongoing tensions that exist between settler society and Indigenous peoples (Walter et al., 2011; Wolfe, 1999). All authors are qualified social workers with a keen sense of social justice underpinning the motivation 
for this study, that is, to support Indigenous fathers, their families, and communities to continue to grow strong.

\section{Participants}

The data analysed in this paper is from Wave 5 (B and K Cohort) of the Longitudinal Study of Indigenous Children (LSIC), an Australian mainland dataset collected annually by the Federal Department of Social Services (2018). The first Wave of data collection begun in 2008, at which time there were 1,671 $(N)$ children that participated. These participants were categorised into the Baby Cohort (B Cohort) (aged 6 - 18 months) and Kid Cohort (K Cohort) (aged 3.5 - 5 years). The dataset also asks questions of primary caregivers (mostly mothers), secondary caregivers (mostly fathers), and teachers. Data are collected annually by Research Administration Officers (RAOs) who generally belong to the local Indigenous community. The Wave 5 data analysed in this paper were collected in 2012. There were 180 Indigenous and non-Indigenous fathers (all P2s ${ }^{4}$ ) who participated in the sample. Of these, there were 112 Indigenous fathers and 68 non-Indigenous fathers. The relationship these 112 Indigenous fathers had with their children were: 106 biological fathers; 4 stepfathers; 1 adoptive or foster father; and 1 grandfather. The age range for these Indigenous fathers was 22 to 68 years with a mean of 37.75 years.

\section{Data Analysis}

The primary method used in this paper was the content analysis (Churchill, 2019) of short qualitative responses regarding the question : "what's the best thing about being $<$ Study Childs $><$ Dad/Dad relationship $>$ ? Answer specified” (item bdi1_t). Content analysis is a method whereby themes and reoccurring patterns within texts are developed (Churchill,

\footnotetext{
${ }^{4}$ In the LSIC dataset, the term P2s refers to secondary caregivers, while P1s are primary caregivers.
} 
2019). Texts can include a wide range of sources such as newspaper articles, court reports, parliamentary transcripts, and short qualitative responses such as those analysed in this paper. The primary author developed analytic themes with reference to published literature and lived experience of being Worimi (Aboriginal) and actively involved in his local Aboriginal community, other authors then reviewed the themes making suggestions for enhancement.

The LSIC data from Wave 5 were opened with the statistical analysis program SPSS (Version 26). ${ }^{5}$ The variable 'Dad's Indigenous status' (bhh5p2) was re-coded as a new variable 'Dad_Indigenous_Status’ which contained [0] No: Non-Indigenous and [1] Yes: Indigenous. The operation 'split file' was run and the new variable 'Dad_Indigenous_Status' $(N=180)$ was selected to split Indigenous (Aboriginal, Torres Strait Islander, and Aboriginal and Torres Strait Islander) $(n=112)$ and non-Indigenous $(n=68)$ fathers. Then, the question "Can you tell me - what's the best thing about being [Study Child's] [Dad/ Dad relationship]?” (Item bdi1) was posed. All 112 Indigenous fathers specified an answer. These Indigenous fathers were then asked, "what's the best thing about being $<$ Study child $>$ 's $<$ Dad/Dad relationship?" (bdi1_t) and provided short qualitative responses ranging from one word to three sentences.

\section{Results}

The results regarding the question asked of Indigenous fathers what's the best thing about being your child's dad (bdi1_t) were spread across 13 themes as displayed in Figure 1. There was a total of 168 content units with an average of 1.5 content units per respondent.

\footnotetext{
${ }^{5}$ SPSS is a statistical analysis software package owned by IBM (Peacock, H. 2019; Walter 2013).
} 


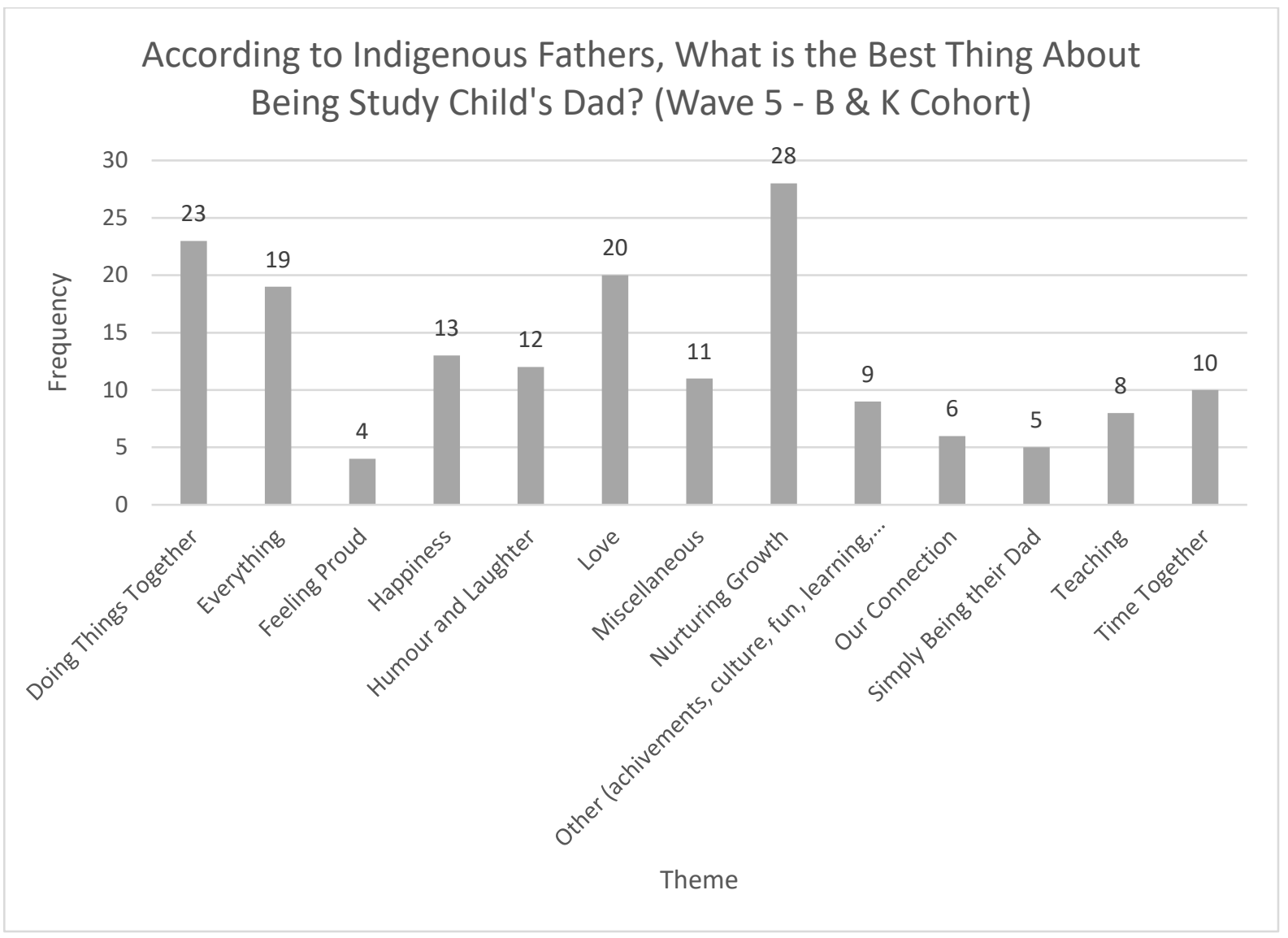

Figure 1: According to Indigenous Fathers what is the Best Thing About being their Child's Dad? (Wave 5 - B \& K Cohort) (bdi1_t).

\section{Nurturing growth}

The most prominent theme was 'nurturing growth'. Responses gathered into this theme represent 16 percent $(n=28)$ of the content units. The responses categorised as 'nurturing growth' included care for their child to grow physically and mentally, assisting their child's progression through their formative years, and providing them with necessary life skills. Some responses provided by Indigenous fathers included:

"It's good to see them growing up, I try to give them things that I didn't get when I was growing";

“The enjoyment of him achieving things and growing up. And giving him the things I never had"; and 
"Watching him grow up and go through different stages and overcoming different times”.

These statements situate fathers at the centre of their children's lives, not only witnessing but also actively contributing to their child growing and developing skills. The appearance of 'things I didn't get' offers potential insight into the personal impacts of structural and racist events such as colonisation and the Stolen Generations (Dudgeon et al., 2014). These comments suggest an intent to engage as a father, to actively parent their child (which may simultaneously offer some healing from an experience they missed themselves as a child), and experiencing a delight in the growing up of their child. This element of delight can be seen as a thread through other themes identified here.

\section{Doing things together}

The second highest scoring theme from the content analysis was 'doing things together' which consisted of 14 percent $(n=23)$ of all content units. The theme of 'doing things together' consisted of the type of activities and events Indigenous fathers undertook with their child such as sport, playing games, spending time together, fun, Indigenous cultural activities, and taking them to school related events. This theme included responses such as:

"Get to wake up in the morning and take her to school watch her play netball and other sports";

"I like spending time with my kids, going to parks and the zoo"; and

"Just when I take him to places that he has not seen and see his face light up with all the new things he sees”.

Doing things together augments the first theme of 'nurturing growth'. In some respects, doing things together can be understood as the relational vehicle through which nurturing growth 
occurs. Delight makes an appearance in this theme as well, in experiencing their child's delight in having new experiences.

\section{Love}

The third highest scoring theme was 'love' which contained 12 percent $(n=20)$ of all content units. The theme of love included ways which Indigenous fathers express love to their child, how their child expresses love to them, and how love and affection are shared between Indigenous fathers and their child. This theme highlights the significance of the relationship shared by Indigenous fathers and their child by the expression of love. The theme of 'love' included content such as:

"The unconditional love I get from him";

"She comes and gives me a hug and tells me she loves me"; and

“I Love being her Dad”.

\section{Everything}

The fourth highest scoring theme was 'everything' which had 11 percent $(n=19)$ of the total content units. The theme of 'everything' consisted of Indigenous fathers not being able to choose just one aspect that was the best thing about being an Indigenous father, rather everything was considered the best. The theme of 'everything' included responses such as:

“Everything - she has a great sense of humour”;

"Lot of things, being Aboriginal and where we are from and who we are"; and "Everything - he is funny kid, he is going to be a good sportsman, very energetic, just good to have a round, take him to work with me, he loves doing things for people, loves his extended family”. 


\section{Additional themes on relationality}

The remaining data from the question: "what's the best thing about being [Study Child's] [Dad/ Dad relationship]?” were categorised into nine themes. These themes are 'Feeling Proud' ( $n=4)$, 'Happiness' ( $n=13)$, 'Humour and Laughter' ( $n=12)$, 'Miscellaneous' $(n=11)$, 'Other (inclusive of achievements, fun, learning, relationships, and sharing Indigenous culture)' ( $n=9)$, 'Our Connection’ ( $n=6)$, 'Simply Being their Dad' $(n=5)$, 'Teaching' $(n=8)$, and 'Time Together' $(n=10)$. The themes consisted of responses which centre relationality: fathers' deep connection with their child and the many ways in which Indigenous fathers described the best thing about being their child's parent.

\section{Discussion}

\section{Indigenous Fathering and Relationality, A Strengths-Based Approach}

In Australia, the centrality of relationality for Indigenous people inclusive of identity, where they belong (Country, community, and mob), and how to be (connection with Country and Indigenous community) is explored by other scholars (Colquhoun \& Dockery, 2012; Dockery 2020; Martin 2008; Walter et al., 2017). As illuminated in our analysis of responses to the question “what's the best thing about being $<$ Study child $>$ 's $<$ Dad/Dad Relationship $>$ ?”, there are a variety of ways which Indigenous fathers describe how they are wholeheartedly connected and fulfilling the relationship they hold with their children (see Figure 1). While it has been a rare focus in existing research literature, some studies have begun exploring the relationship between Indigenous fathers and their children. Prehn et al. (2020) explore the importance of relationships Indigenous fathers have with their children, and the participation in and sharing of Indigenous cultural practices together. Similarly, Collard et al. (2016) highlight the importance of Indigenous (specifically Noongar) fathering epistemes, and enriching different aspects of the relationship between father and child such as sharing 
Indigenous culture, spending time together, and being strong in their Indigenous Identity, while Canuto et al. (2019) detail the importance of Indigenous fathers being actively engaged in meaningful relationships with their children despite experiencing ongoing structural disadvantage. There are now several studies which highlight the significance of relationships Indigenous fathers have with their children and the value placed on relationality.

The use of a strengths-based approach in the Indigenous fathering sphere has steadily grown over the last decade (Canuto et al., 2020). This is an important corrective to the unfair, racist, and inaccurate deficit narrative dominating public discourse about Indigenous men, their fathering specifically, as well as Indigenous parenting more broadly (see for example ABC News (2016a), Wild and Anderson (2007), Krakouer (2019), and Hunter et al. (2020)). Using a strengths-based approach in research, and asking strength-based questions such as the question explored in this paper "what's the best thing about being $<$ Study child $>$ 's $<$ Dad/Dad Relationship>?”, offers a meaningful method to challenge deficit narratives; which for Indigenous peoples are rooted in the ongoing process of settler colonialism (Fogarty et al., 2018; Saleebey, 1996). Strengths-based approaches to Indigenous fatherhood (and other components of Indigenous masculinity (Prehn 2021)) are needed to push back against the structure of settler colonialism (Wolfe, 1999), and racist processes such as the 'othering' of Indigenous fathering epistemes (Hunter et al., 2020).

\section{Collaborating with Indigenous fathers: implications for social work}

These findings have implications for those collaborating with Indigenous fathers in the field of social work and other professions. Deficit-based and colonising biases relating to Indigenous fathers are part of the settler society within which social work practice exists. Social workers and other professionals are equally prone to these biases as members of this society. An essential first step for those collaborating with Indigenous fathers is to critically 
reflect on any biases they may consciously or unconsciously hold, and challenge the normalisation of White middle-class approaches to parenting (Hunter et al., 2020). Critical reflection on practice is vital to identify and de-naturalise these biases in overt and latent messages present in social worker's or other professional's collaboration with Indigenous fathers and families.

Biases pertaining to Indigenous fathers (and other parents) may be contributing to the disturbingly high rates of Indigenous child removal (Hunter et al., 2020; Krakouer, 2019). In 2020, Indigenous children made up $41 \%$ of the total out of home care population, despite being only 5.5\% of the total Australian child population (Australian Institute of Health and Welfare, 2021) while in 2019-2020, Indigenous children were 11 times more likely to be living in out-of-home care than non-Indigenous children. Critical reflection coupled with a strengths-based approach in the realm of Indigenous fathering (and parenting more generally) is necessary to provide adequate supports to assist in child rearing. These supports may be particularly necessary when considering the ongoing structure of settler colonialism, which marginalises Indigenous fathering epistemes, and privileges White middle-class fathering perspectives (Fredericks, 2009; Hunter et al., 2020; Wolfe, 1999).

If the strategy to combat persistent deficit saturated narratives about Indigenous fathers is to be challenged by critical reflection, it is important to note that in a settler colonial society, critical reflection can only unmask racial biases if, at some point, there is input to the reflective process by Indigenous fathers themselves. As Social workers often work in ‘bubbles’ of White privilege (Walter and Baltra-Ulloa, 2021), this means even in their engagement with critical reflective processes they are likely to reproduce White privilege if they do not have a direct relationship with Indigenous fathers. This is an element of 
relationality that is often missed and that we in this paper suggest proves vital to dismantling settler colonial power differentials and to bolstering the merits of strength-based approaches.

According to the 2020 Family Matters Report the causes for Indigenous child removal are complex. However, the main causes are: perceptions arising from cultural differences in child-rearing practices; inter-generational trauma; the legacy of past policies of forced removal, and a higher likelihood of living in the lowest socioeconomic areas (Hunter et al., 2020). Many components of these four causes can be linked to the ongoing structure of settler colonialism (Dudgeon et al., 2014; Walter et al., 2017; Wolfe 2006). Lewis et al. (2019) advocate that a first solution to the excessive rates of Indigenous child removal is access to universal and targeted services, which includes an investment in early intervention and prevention focused child and family services. The specific supports required by Indigenous fathers can vary but may include individual assistance (Canuto et al., 2018; Prehn \& Ezzy, 2020), access to culturally appropriate fathering groups (Canuto et al., 2020; Collard et al., 2016), participation and control in decision making of areas pertaining to their lives, and culturally safe and responsive policies (Australian Department of Health and Ageing, 2010). The social work profession has a key role to play regarding the empowerment of Indigenous fathers (and their families) to uphold the essential place of relationality for enabling being, belonging, and connection for Indigenous children, fathers, families, and communities (Dockery 2020; Graham 2014). Social work’s ethical and professional responsibilities must ensure adequate supports are accessible, rather than relationality being unnecessarily disrupted by biases founded in unfair and inaccurate settler colonial deficit narratives.

\section{Limitations}

The main limitation of this paper is the use of short qualitative secondary data. Because the data had already been collected and comprised short qualitative answers from a larger primary 
quantitative survey, there was not the depth achievable in long qualitative studies. A qualitative study exploring similar strengths-based questions with Indigenous fathers would be a meaningful direction for further investigation to build upon this paper. Our proximity to relationality in this study is reduced by the exclusive reliance on this data. However, we have argued that our methods, analysis, and conclusions have provided the opportunity to open up a critical debate yet to become expansive.

\section{Conclusion}

Use of strengths-based approaches to Indigenous fathering in Australia and subsequent sharing of these narratives are important to displace deficit-based thinking. Using Indigenous standpoint theory (Foley 2003) we explored data from the Longitudinal Study of Indigenous Children (LSIC) Wave 5 (B \& K Cohort). Content analysis was used to understand what according to Indigenous fathers was the best thing about being their child's dad. The results were spread across 13 themes and show the variety of ways Indigenous fathers are positively engaged in their child's life. Key themes of doing things together; nurturing growth; sharing love; and "everything” represent the significance of relationality for Indigenous fathers and their children.

For those collaborating with Indigenous fathers and their families, engaging in critical reflection on biases is vital to enhance collaboration and displace the normalisation of White middle-class worldviews. Critical reflection processes must also be relational and engage directly with Indigenous fathers. Greater understanding of the structural disadvantage experienced by Indigenous fathers, their families, and communities because of the ongoing process of settler colonialism, will contribute to a wider less racist perception of Indigenous fathering, empowerment of a strength-based approach to understanding and supporting Indigenous fathering, and proper access to needed supports. Subsequently, this may lead to 
reducing disturbingly high rates of Indigenous children removal from their fathers, mothers, families, and communities, leading to Indigenous families continuing to grow strong.

\section{Acknowledgements}

We would like to acknowledge the Aboriginal and/or Torres Strait Islander participants in the Longitudinal Study of Indigenous Children. We would also like to acknowledge the anonymous reviews. Thank you.

This paper uses unit record data from Longitudinal Study of Indigenous Children (LSIC). LSIC conducted by the Australian Government Department of Social Services (DSS). The findings and views reported in this paper, however, are those of the authors and should not be attributed to the Australian Government, DSS, or any of DSS' contractors or partners. DOI: 10.26193/SSWEX1.

\section{Declaration of Interest}

The authors of this paper have no conflicts of interested to declare.

\section{Data Availability Statement}

The data that support the findings of this study are available the Australian Federal Department of Social Services. Restrictions apply to the availability of these data, which were used under license for this study. Data are available the Department of Social Services at https://www.dss.gov.au/about-the-department/publications-articles/researchpublications/longitudinal-data-initiatives/footprints-in-time-the-longitudinal-study-ofindigenous-children-lsic with the permission of the Department of Social Services.

\section{References}


ABC News. (2016a). Bill Leak cartoon in The Australian an attack on Aboriginal people, Indigenous leader says. ABC News. Retrieved 19/06/2018 from http://www.abc.net.au/news/2016-08-04/cartoon-an-attack-on-aboriginal-people,indigenous-leader-says/7689248

ABC News. (2016b). \#IndigenousDads counter Bill Leak cartoon with stories of fatherhood. Retrieved 06/19/2018 from http://www.abc.net.au/news/2016-08-06/indigenous-dadscounter-bill-leak-cartoon-with-stories/7697668

Armstrong, S., Buckley, S., Lonsdale, M., Milgate, G., Kneebone, L. B., Cook, L., \& Skelton, F. (2012). Starting school: a strengths-based approach towards Aboriginal and Torres Strait Islander children. Australian Council for Educational Research.

Australian Department of Health and Ageing. (2010). National Aboriginal and Torres Strait Islander Male Health Framework - Revised Guiding Principles (Australian Department of Health and Ageing, Issue.

Australian Institute of Health and Welfare. (2021). Child protection Australia 2019-20. Retrieved 03/08/2021 from https://www.aihw.gov.au/reports/child-protection/childprotection-australia-2019-20/summary

Bainbridge, R., Whiteside, M., \& McCalman, J. (2013). Being, Knowing, and Doing:A Phronetic Approach to Constructing Grounded Theory With Aboriginal Australian Partners. Qualitative health research, 23(2), 275-288. https://doi.org/10.1177/1049732312467853

Barker, A., \& Lowman, E. B. (2020). Global Social Theory: Settler Colonialism. Retrieved 08/12/2020 from https://globalsocialtheory.org/concepts/settler-colonialism/

Bringing Them Home. (1997). Report of the National Inquiry into the separation of Aboriginal and Torres Strait Islander children from their families. Sydney: Human Rights and Equal Opportunity Commission. 
Brough, M., Bond, C., \& Hunt, J. (2004). Strong in the City: towards a strength-based approach in Indigenous health promotion. Health Promotion Journal of Australia, 15(3), 215-220.

Canuto, K., Harfield, S. G., Canuto, K. J., \& Brown, A. (2020). Aboriginal and Torres Strait Islander men and parenting: a scoping review. Australian Journal of Primary Health, 26(1), 1-9.

Canuto, K., Towers, K., Riessen, J., Perry, J., Bond, S., Ah Chee, D., \& Brown, A. (2019).

"Anybody can make kids; it takes a real man to look after your kids": Aboriginal men's discourse on parenting. PloS one, 14(11), e0225395-e0225395.

https://doi.org/10.1371/journal.pone.0225395

Canuto, K., Wittert, G., Harfield, S., \& Brown, A. (2018). “I feel more comfortable speaking to a male”: Aboriginal and Torres Strait Islander men’s discourse on utilizing primary health care services [journal article]. International Journal for Equity in Health, 17(1), 185. https://doi.org/10.1186/s12939-018-0902-1

Churchill, B. (2019). Content Analysis. In M. Walter (Ed.), Content Analysis (4th ed., pp. 296-315). Oxford University Press.

Collard, L., Adams, M., Palmer, D., \& McMullan, J. (2016). Quop Maaman: Aboriginal Fathering Project. T. F. Project.

Colquhoun, S., \& Dockery, A. M. (2012). The link between Indigenous culture and wellbeing: Qualitative evidence for Australian Aboriginal peoples. The Centre for Labour Market Research, 1-29.

Department of Social Services. (2018). Footprints in Time - The Longitudinal Study of Indigenous Children (LSIC). Australian Government. https://www.dss.gov.au/aboutthe-department/publications-articles/research-publications/longitudinal-datainitiatives/footprints-in-time-the-longitudinal-study-of-indigenous-children-lsic\#1 
Dockery, A. M. (2020). Inter-generational transmission of Indigenous culture and children’s wellbeing: Evidence from Australia. International Journal of Intercultural Relations, 74, 80-93.

Dudgeon, P., Wright, M., Paradies, Y., Garvey, D., \& Walker, I. (2014). Aboriginal social, cultural and historical contexts. In Working together Aboriginal and Torres Strait Islander mental health and wellbeing principles and practice. (pp. 3-24). Australian Government.

Elliott, K., \& Roberts, S. (2020). Balancing generosity and critique: Reflections on interviewing young men and implications for research methodologies and ethics. Qualitative Research, 20(6), 767-783.

Fogarty, W., Lovell, M., Langenberg, J., \& Heron, M.-J. (2018). Deficit discourse and strengths-based approaches: changing the narrative of Aboriginal and Torres Strait Islander health and wellbeing. Deficit Discourse and Strengths-based Approaches: Changing the Narrative of Aboriginal and Torres Strait Islander Health and Wellbeing, viii.

Foley, D. (2003). Indigenous epistemology and Indigenous standpoint theory. Social Alternatives, 22(1), 44.

Fredericks, B. L. (2009). The epistemology that maintains white race privilege, power and control of Indigenous Studies and Indigenous peoples' participation in universities. Australian Critical Race and Whiteness Studies Association eJournal, 5(1), 1-12.

Gee, G. D., P., Schultz, C., Hart, A., \& Kelly, K. (2014). Aboriginal and Torres Strait Islander Social and Emotional Wellbeing. In P. Dudgeon, Milroy, P. \& Walker, R (Ed.), Working together: Aboriginal and Torres Strait Islander Mental Health and Wellbeing Principles and Practice, . Commonwealth of Australia. 
Geertz, C. (1973). Thick description: Toward an interpretive theory of culture. Turning points in qualitative research: Tying knots in a handkerchief, 3, 143-168.

Graham, M. (2014). Aboriginal notions of relationality and positionalism: a reply to Weber. Global Discourse, 4(1), 17-22.

Hunter, S., Burton, J., Blacklaws, G., Soltysik, A., Mastroianni, A., Young, J., Jones, M., Jayakody, N., Bhathal, A., \& Krakouer, J. (2020). The Family Matters Report 2020. Measuring trends to turn the tide on the over-representation of Aboriginal and Torres Strait Islander children in out-of-home care in Australia.

Konishi, S. (2011). Representing Aboriginal Masculinity in Howard's Australia. In R. Jackson \& M. Balaji (Eds.), Global masculinities and manhood. University of Illinois Press.

Krakouer, J. (2019). The stolen generations never ended - they just morphed into child protection. The Guardian. Retrieved 17/09/2020 from https://www.theguardian.com/commentisfree/2019/oct/17/the-stolen-generationsnever-ended-they-just-morphed-into-child-protection

Males in Black Inc., \& Wesley, U. (2006). Aboriginal Dads Program: Support young Aboriginal fathers in positive parenting and community involvement through mentoring. C. a. F. C. Australia.

Martin, K. (2008). Please knock before you enter: Aboriginal regulation of outsiders and the implications for researchers. Post Pressed.

Morgensen, S. L. (2015). Cutting to the roots of colonial masculinity. In R. Innes \& K. Anderson (Eds.), Indigenous Men and Masculinity (pp. 38-61). University of Manitoba Press.

Newell, S., Franks, A., Lloyd, D., Telford, G., \& Binge, C. (2006). Koori Fathering Program: pilot phase evaluation report. 
Peacock, H. (2019). Descriptive Statistical Analysis using SPSS. In M. Walter (Ed.), Social research methods (4th ed.). Oxford Univeristy Press.

Prehn, J. (2021). "We've always done it. Country is our counselling office": masculinity, nature-based therapy, and the strengths of Aboriginal men.

Prehn, J., \& Ezzy, D. (2020). Decolonising the health and well-being of Aboriginal men in Australia. Journal of Sociology, 56(2), 151-166.

\section{https://doi.org/10.1177/1440783319856618}

Prehn, J., Guerzoni, M. A., \& Peacock, H. (2020). 'Learning her culture and growing up strong': Aboriginal and/or Torres Strait Islander fathers, children and the sharing of culture. Journal of Sociology.

Priest, N., Mackean, T., Davis, E., Waters, E., \& Briggs, L. (2012). Strengths and challenges for Koori kids: Harder for Koori kids, Koori kids doing well-Exploring Aboriginal perspectives on social determinants of Aboriginal child health and wellbeing. Health Sociology Review, 21(2), 165-179.

Rapp, C. A. (1997). The strengths model: Case management with people suffering from severe and persistent mental illness.

Reilly, L., \& Rees, S. (2018). Fatherhood in Australian Aboriginal and Torres Strait Islander communities: An examination of barriers and opportunities to strengthen the male parenting role. American journal of men's health, 12(2), 420-430.

Ritchie, J. (2013). Sustainability and Relationality Within Early Childhood Care and Education Settings in Aotearoa New Zealand. International Journal of Early Childhood, 45(3), 307-326. https://doi.org/10.1007/s13158-013-0079-0

Saleebey, D. (1996). The strengths perspective in social work practice: Extensions and cautions. Social Work, 41(3), 296-305. 
Tsey, K., Wilson, A., Haswell-Elkins, M., Whiteside, M., McCalman, J., Cadet-James, Y., \& Wenitong, M. (2007). Empowerment-based research methods: a 10-year approach to enhancing Indigenous social and emotional wellbeing. Australasian Psychiatry, 15(1), S34-S38.

Walker, R., \& Shepherd, C. (2008). Strengthening Aboriginal family functioning: What works and why? Australian Institute of Family Studies Melbourne (AUST).

Walter, M. (2013). The Nature of Social Science Research. In M. Walter (Ed.), Social research methods (3rd ed.). Oxford University Press.

Walter, M and Baltra-Ulloa, AJ. (2021). An ethics framework embedded in an Indigenous epistemology: implications for social work research and practice, Aboriginal Fields of Practice, Macmillan Education, B Bennett (ed), United Kingdom (2021).

Walter, M., Martin, K. L., \& Bodkin-Andrews, G. (2017). Indigenous Children Growing Up Strong: A Longitudinal Study of Aboriginal and Torres Strait Islander Families. Springer.

Walter, M., Taylor, S., \& Habibis, D. (2011). How white is social work in Australia? Australian Social Work, 64(1), 6-19.

Whiteside, M., Klieve, H., Millgate, N., Webb, B., Gabriel, Z., McPherson, L., \& Tsey, K. (2016). Connecting and Strengthening Young Aboriginal Men: A Family Wellbeing Pilot Study [Article]. Australian Social Work, 69(2), 241-252. https://doi.org/10.1080/0312407X.2015.1137101

Wild, R., \& Anderson, P. (2007). Little children are sacred. Report of the Northern Territory Board of Inquiry into the Protection of Aboriginal Children from Sexual Abuse.

Wolfe, P. (1999). Settler colonialism. A\&C Black.

Wolfe, P. (2006). Settler colonialism and the elimination of the native. Journal of Genocide Research, 8(4), 387-409. 

Figure 1:

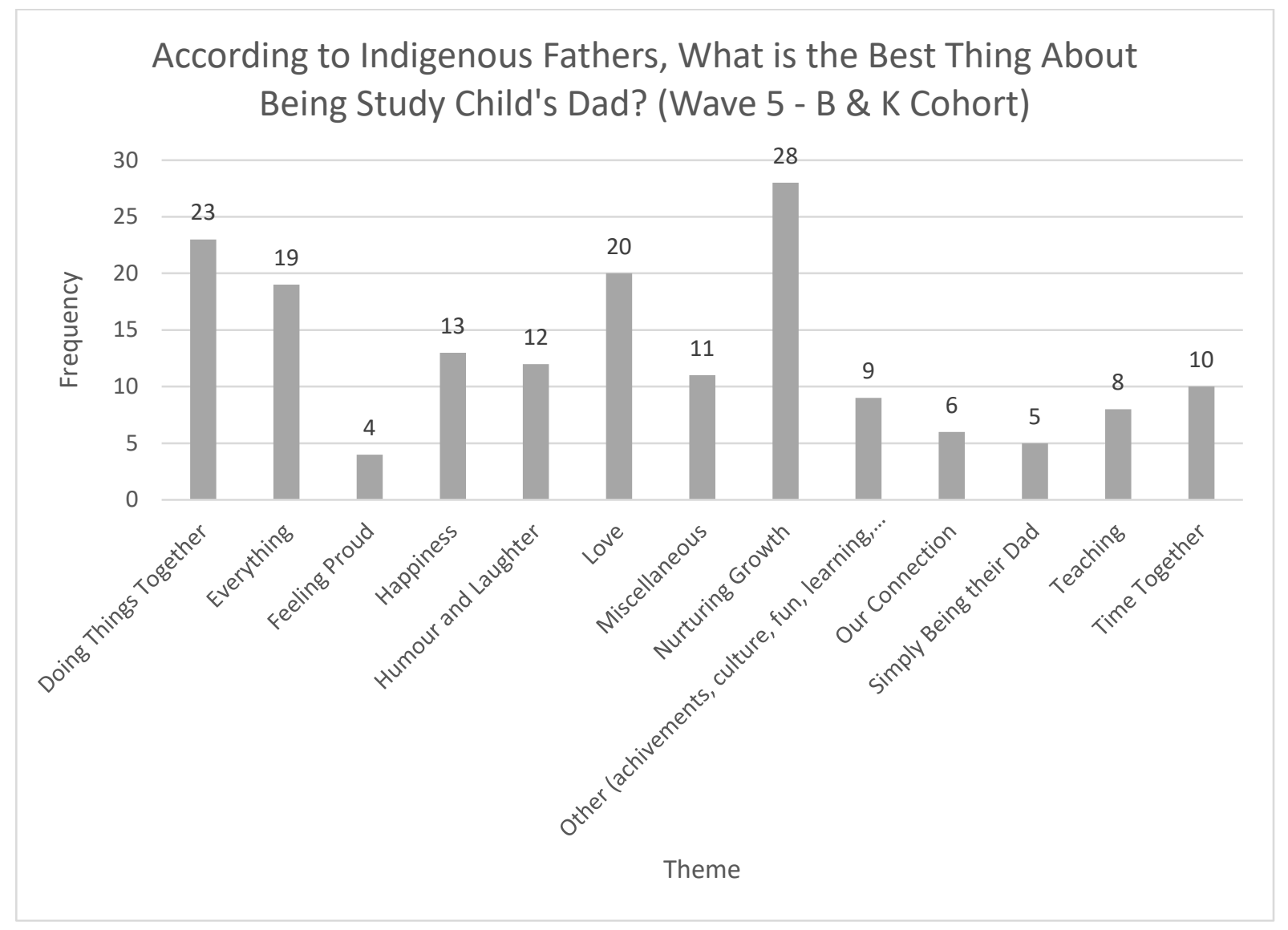

